Article

\title{
Automated Extraction of Shallow Erosion Areas Based on Multi-Temporal Ortho-Imagery
}

\section{Christoph Wiegand $^{1}{ }^{*}$, Martin Rutzinger ${ }^{1,2}$, Kati Heinrich ${ }^{2}$ and Clemens Geitner ${ }^{1}$}

1 Institute of Geography, University of Innsbruck, Innrain 52, 6020 Innsbruck, Austria;

E-Mails: martin.rutzinger@uibk.ac.at (M.R.); clemens.geitner@uibk.ac.at (C.G.)

2 Institute for Interdisciplinary Mountain Research, Austrian Academy of Sciences, Technikerstr. 21a, Otto Hittmair-Platz 1, 6020 Innsbruck, Austria; E-Mails: martin.rutzinger@oeaw.ac.at (M.R.); kati.heinrich@oeaw.ac.at (K.H.)

* Author to whom correspondence should be addressed; E-Mail: christoph.wiegand@uibk.ac.at; Tel.: +43-512-507-49410; Fax: +43-512-507-49499.

Received: 30 March 2013; in revised form: 2 May 2013 / Accepted: 2 May 2013 /

Published: 13 May 2013

\begin{abstract}
In several areas of the Alps, steep grassland is characterized by shallow erosions. These erosions represent a hazard through the increased availability of unconsolidated material in steep locations, loss of soil and impaired landscape aesthetics. Generally, the erosions concern only small areas but sometimes occur in large numbers. Remote sensing technologies have emerged as suitable tools to study the spatio-temporal changes of these eroded areas. The detection of such eroded areas is often done by manual digitalization of aerial photographs, which is labour-intensive and includes a certain risk of subjectivity. In this study we present a methodological tool that allows the automatic classification of shallow erosions on the basis of orthophoto series. The approach was carried out within a test site in the inner Schmirn Valley, Austria. The study covers both the detection of erosion areas and a multi-temporal analysis of the geomorphological changes. The presented approach is an appropriate tool for detecting shallow erosions and for analysing them in multi-temporal terms. The multi-temporal analysis revealed one period of higher increases in eroded areas compared to shrinking during the other periods. However, the analysis of the change of all single erosions indicates that in each study period there was both increase and decrease of erosion areas. The differences in the rates of increase between the observation years are most likely due to the irregular occurrence of events that encourage erosion. In contrast, the rates of decrease are almost constant and suggest a continuous rate of recovery.
\end{abstract}


Keywords: shallow erosion; segmentation; change detection; Alps

\section{Introduction}

Various grassland areas on steep slopes in the Alps have been abandoned as a result of structural changes in mountain agriculture [1-3] and may lead to an increase in shallow erosion areas [4-6]. In this context the influence of climate change has also been mentioned, i.e., whether changes in precipitation patterns and intensity lead to higher risk of erosion [7-10]. In general these erosion processes are not systematically registered nor inventoried in Alpine regions and there is still some uncertainty about the main causal factors. In some regions these shallow erosions can yield substantial amounts of unconsolidated material. In combination with heavy rainfall, the denudation and mobilization of material increases the danger of hazards such as landslides and debris flows reaching intensively used or even populated areas. Apart from the dislocation of slope material, the resulting impairment of landscape appeal has a negative impact, especially in tourist regions. For example, Gobster et al. [11] state that noticeable impacts such as visible erosion may be seen as unattractive.

The assessment of the spatio and temporal changes of geomorphological elements is often conducted using geographic information systems (GIS) and remote sensing techniques to analyse satellite and aerial imagery [12-16]. Manual interpretation of aerial photographs is a common technique for landslide mapping and multi-temporal change detection analysis [17-19]. Methods such as pixel-based [20,21] or object-based classification techniques [22] aim for a high degree of automation and improved comprehensibility of results [23-27]. In this study we concentrate on mapping shallow and small eroded areas of a size between $2 \mathrm{~m}^{2}$ and $200 \mathrm{~m}^{2}$ [28] and a depth between a few decimetres and $2 \mathrm{~m}[29,30]$. Hence the dislocation of material per single eroded area is relatively small. However, considering the total number of such erosion areas, the displacement and the spatial distribution can be considerable ( $>30$ areas per ha). Shallow landslides and snow gliding can cause these kinds of small and shallow erosions [31,32]. Once the primary material displacement has occurred, secondary fluvial erosion processes often enlarge the eroded areas [32]. It must be said that it is not possible to identify the processes causing this kind of erosion using the available optical remote sensing data (Section 3). Therefore we will use the general term "eroded areas" to describe the geomorphological elements investigated in this study without specifying the underlying process.

Delineation procedures are often designed to generate objects with crisp boundaries. However, uncertainties of sensor properties (e.g., resolution and target scale) and uncertainties from data pre-processing (geometric and radiometric correction) lead to uncertainties of the object representation in remote sensing data and furthermore to uncertainties in the definition of object boundaries. These uncertainties are taken into account by calibrating the detection procedure using, e.g., training data. Misclassification and delineation errors are expressed e.g., by calculating error measures. However, the investigation of the influence of different parameter settings on delineation results is often not presented. The concept of vague objects [33,34] — in particular the so-called Egg-Yolk model—is well suited to do so. The object is composed of a core object with high probability of belonging to the object ("yolk") and the transition zone with declining probability belonging to the object ("egg white") [35]. In 
this contribution we present a delineation approach following the idea of the Egg-Yolk model, to present the influence of parameter settings on object delineation (see Section 4) in order to give more insight to the object segmentation parameter settings calibration.

In this paper we present an approach to detecting small eroded areas that uses orthophoto series from aerial imagery. Extraction of eroded and non-eroded areas is realized by implementing a segmentation algorithm based on dynamic thresholds on the distribution of digital numbers (DNs) - also referred to as "pixel value" - from the visible RGB colour bands. To analyse spatio-temporal changes of eroded areas we compare maps derived from the analysis of orthophotos for different years. The objectives of the study are (i) to develop a reliable mapping tool to detect small eroded areas based on orthophotos for different years, (ii) to characterize eroded areas by a differentiated appraisal of increase and decrease over a period of 10 years, and (iii) to evaluate the dynamics of small eroded areas by spatial and temporal analysis.

The paper is structured as follows. After the introduction in Section 1, including related work, Section 2 describes the location and characteristics of the test site. The used data set, i.e., ortho-imagery, is described in Section 3. Section 4 gives a detailed explanation of the implemented segmentation workflow, followed by Section 5 which explains the choice of parameters. The changes in the appearance of eroded areas between 2000 and 2010 is analysed in Section 6, followed by discussion in Section 7. The paper concludes with an outlook in Section 8.

\section{Site Description}

The test site is located on an Alpine slope near the village of Obern in the inner Schmirn Valley (Tyrol, Austria) (Figure 1). The slope contains several recent and historical shallow eroded areas, which indicate a strong susceptibility to and activity of erosion processes.

Figure 1. Location of the test site in Tyrol, Austria.

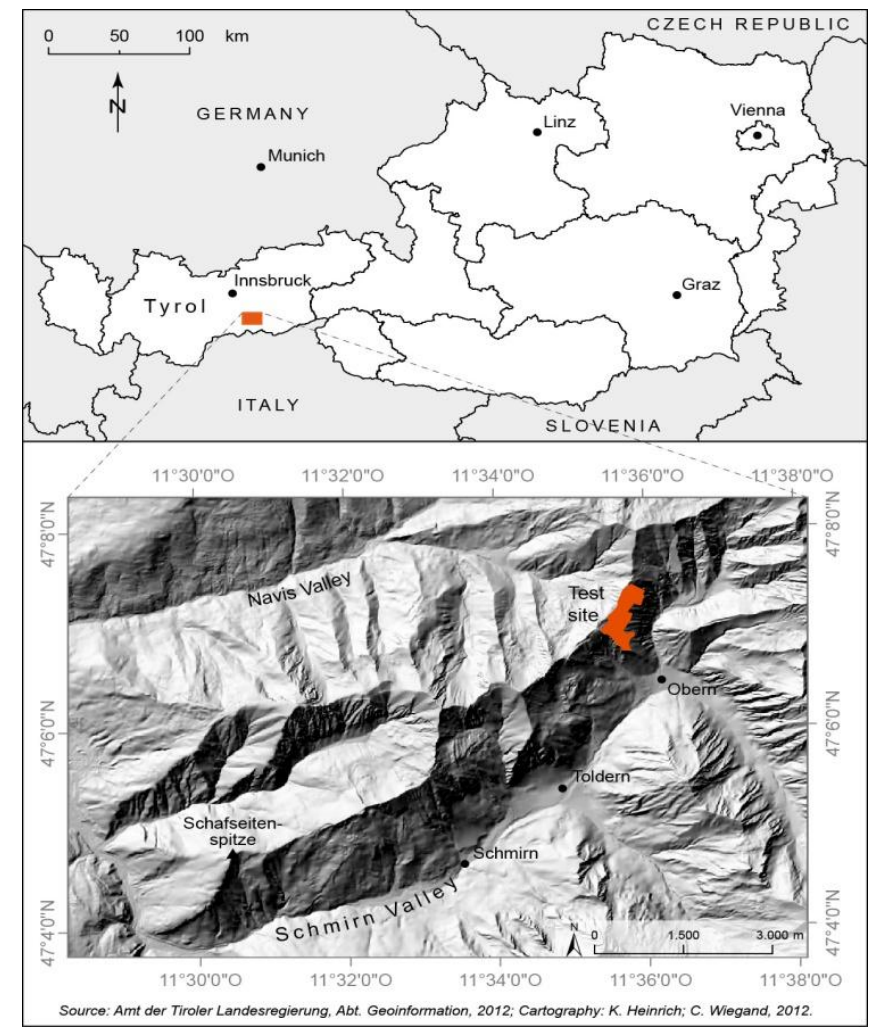


The area of the test site covers 36 ha. Altitude ranges between 1,980 $\mathrm{m}$ and 2,370 $\mathrm{m}$ a.s.l. The mean annual temperature is $2{ }^{\circ} \mathrm{C}$ and annual precipitation is $1,220 \mathrm{~mm}$ (measurement period 1971-2000) [36]. Mean slope inclination is $36^{\circ}$, facing east to southeast. Geologically the entire region is part of the "Tauern Window" and consists mainly of metamorphic rocks [37]. The slope of the test site consists mainly of Bündner schists deficient in lime, covered with few decimetres of regolith [38]. Dominant soil types are shallow developed cambisols and regosols (authors' field survey). The test site is situated in the range of the timberline where the lower part was cleared. The vegetation cover of the test site consists of subalpine and alpine grassland, with dwarf shrubs and single saplings. The slope has been used as meadow and was mowed every second year until the 1960s. According to the local farmers, shallow erosion has always been a problem. To counteract erosion, various measures were taken, such as removing objects that facilitate erosion (e.g., boulders and trunks), filling tension fissures in the surface to hamper the infiltration of water, and sowing fresh eroded areas. Since the 1960s the slope has been used for grazing sheep and no erosion mitigation has been conducted to date.

\section{Data Set}

For the detection of eroded areas we used orthophotos from the official survey campaign of the federal state of Tyrol from the years 2000, 2004, 2007 and 2010 with a resolution of $25 \mathrm{~cm}$ (analogue camera) and $20 \mathrm{~cm}$ for 2010 (digital camera). Additional ortho-imagery between these dates is not available. Each image was taken at the beginning of September, except that of 2007, which was taken in early July [39]. Radiometric differences in the histograms between images can result from differences in sun angle, atmospheric effects, viewing geometry, and instrument response characteristics at the different capture dates [40]. The data provider had already performed radiometric corrections within each campaign, but a radiometric adjustment between the individual images of each year was still needed. The four orthophotos were radiometrically adjusted by applying histogram matching. In histogram matching a lookup table is determined that serves as a function to convert the histogram of one image and match it to the histogram of a second one. The orthophoto of 2004 serves as radiometric reference as it seems to present the best radiometrical correction.

\section{Segmentation Workflow}

The boundary of eroded areas (object of interest) does not appear as a clear line but as a smooth transition to grassland (background) due to uncertainties, e.g., from the limitations of sensor resolution and the relation between target scale and object size [33,41]. The implemented segmentation workflow takes these uncertainties into account.

In a first step a test site is pre-selected, which contains representative small and shallow eroded areas (Figure 2). A dynamic threshold is defined based on each single band of the RGB image. As it is difficult to find the ideal and definite threshold, a range of parameters is used to calculate a band of high probability of being a shallow eroded area. This is implemented by using dynamic threshold $t(j)$ to separate brighter pixels of eroded areas from darker pixels of undisturbed meadows (Figure 3, Equation (1)):

$$
t(j)=\mu+\sigma \times j
$$


where $j$ is the parameter steering the extent of the segmentation results, $\sigma$ is the standard deviation of DNs and $\mu$ is the mean value of DNs within the test site (Figure 4(b,c)). The dynamic threshold is applied to each colour band separately. If a DN is larger than the dynamic threshold it is assigned the value 1 , otherwise the value 0 . The common detected area from all bands (i.e., where DN is equal to 1 in the red AND green AND blue bands) is extracted as a binary layer (layer delineation $_{\text {) }}$ containing areas assigned with 1 for detected area (shallow erosion) and 0 for background (meadow).

Figure 2. Test site near Obern in the inner Schmirn Valley. (a) Test site within the orthophoto; (b) photograph of the southern part of the affected slope.

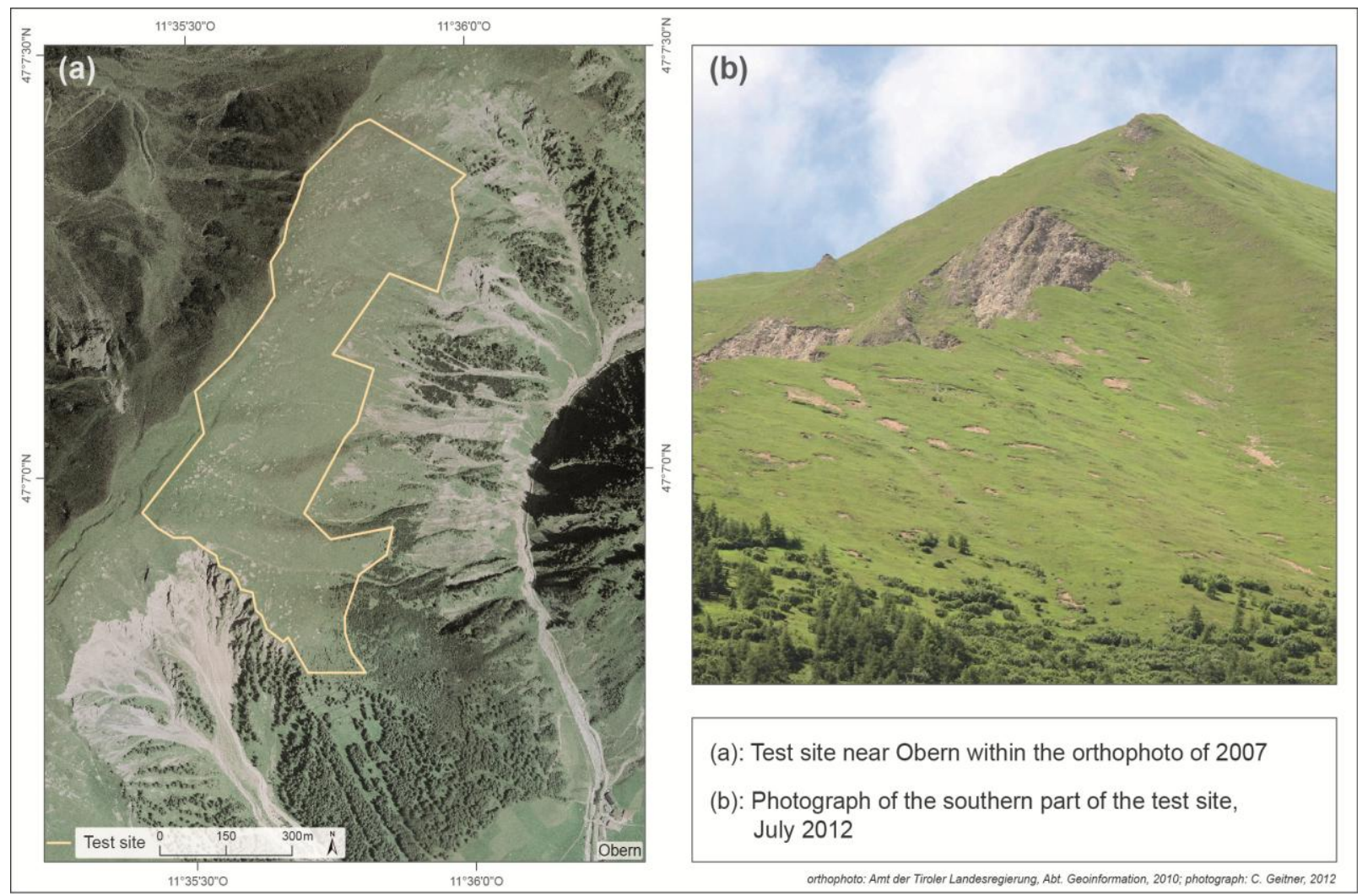

Figure 3. Schematic illustration of setting the dynamic threshold in the distribution of the digital numbers (DNs) of each colour band.

\section{Red}

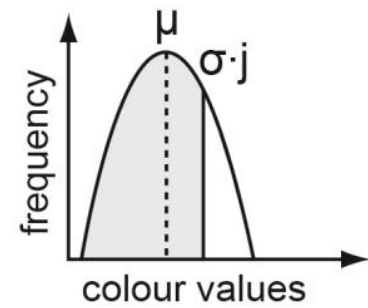

Green

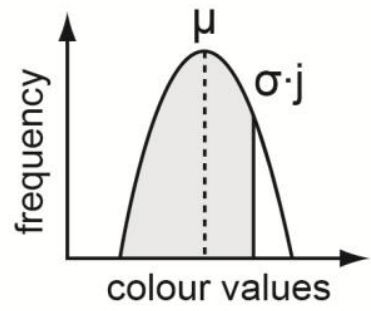

Blue

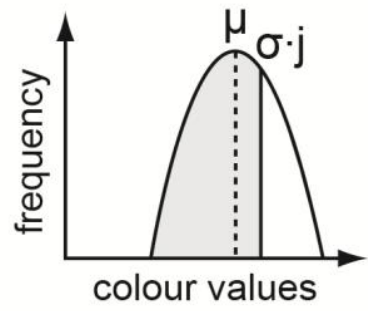

Several layers are calculated within a defined range and step size of $j$. A fuzzy segment boundary is created by summing up the resulting layers for each value of parameter $j$. The summed up layers 
( $\sum$ layer $_{\text {delineation }}$ ) represent the vagueness [34] for delineating eroded areas. Clear segment boundaries have a rather small transition area, while vaguer segment boundaries have a wider distribution between these minimum and maximum counts (Figure 4(b)).

Figure 4. Segmentation steps illustrated on a sample area. (a) Eroded area visible within the orthophoto; (b) sum image ( $\sum$ layer $\left._{\text {delineation }}\right)$ combining all 21 layers; (c) minimum, maximum and expert-assessed segmentation thresholds.

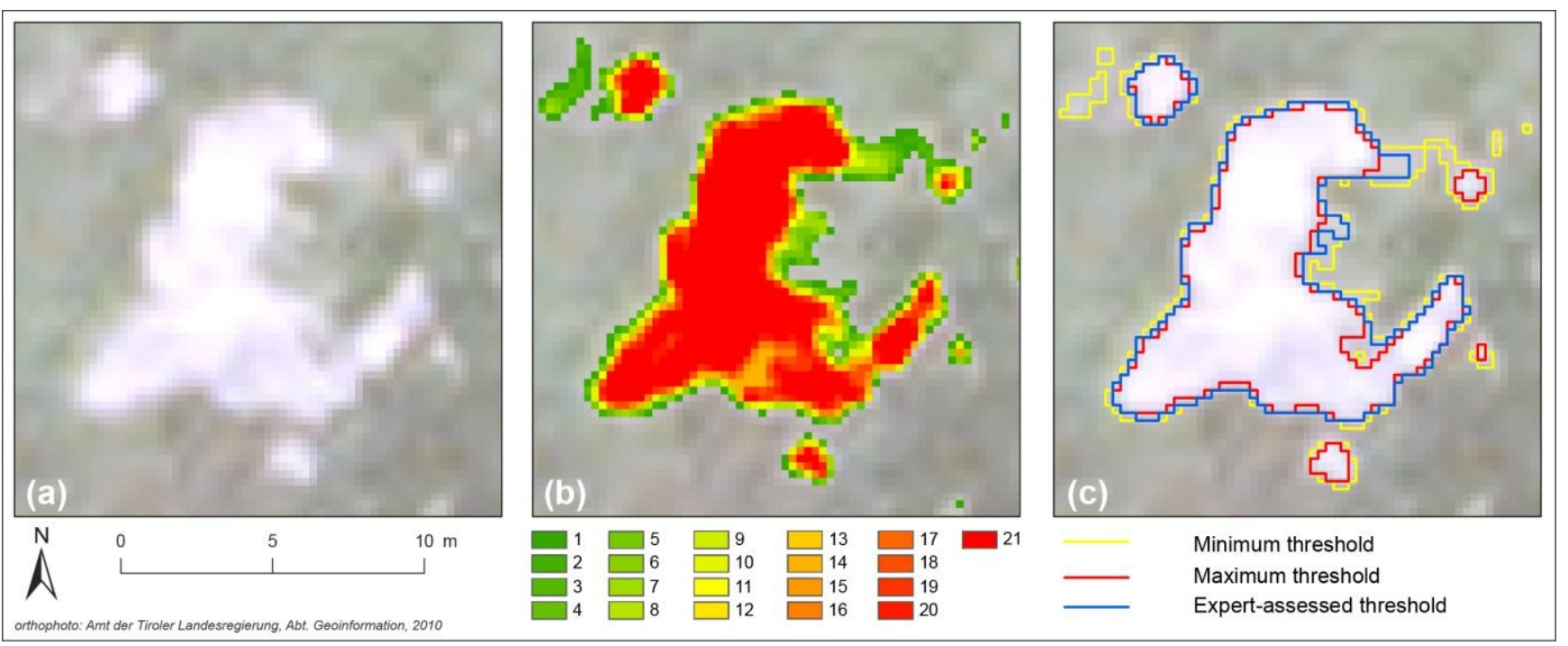

\section{Parameter Setting}

For the given data set, a range $j$ from 1.0 to 3.0 with a step size of 0.1 was found to give most reliable results. This range was chosen because if $j$ is larger than 3.0, the resulting delineation (layer delineation) underestimates the erosion area. This setting produced 21 layers where each pixel contains information on how many times it was classified as erosion, i.e., DNs in $\sum$ layer delineation vary from 1 to 21 (Figure 4(b)). Subsequently the $\sum$ layer $_{\text {delineation }}$ was inspected and compared with the orthophoto by an expert to define the realistic delineation of eroded areas $\left(\sum\right.$ layer $\left._{\text {delineation }}>t_{\text {count }}\right)$. It was found that $t_{\text {count }} \geq 6$ represents eroded areas in the orthophoto of 2000, 2004 and 2007 and $t_{\text {count }} \geq 1$ in the orthophoto of 2010, which is referred to as "expert-assessed" below (Figure 4(c)).

In order to test the robustness of the segment extraction procedure, the changes in number and total area of increasing and decreasing segment parts based on the four data sets are computed. For this purpose a minimum and maximum of $t_{\text {count }}$ is applied to the probability map to investigate the robustness of results. For each year probability maps are calculated using a minimum segmentation threshold $\left(t_{\text {count }} \geq 1\right)$ and a maximum threshold $\left(t_{\text {count }} \geq 9\right)$ to see how much the results might change (Figure 4(c)). Areas smaller than $2 \mathrm{~m}^{2}$ are considered noise and excluded. When comparing two orthophotos of a period, areas that have changed less than $0.01 \mathrm{~m}^{2}$ are considered stable. For the comparison in Figure 5 no limitation on maximum area was applied to reflect the nature of the algorithm and the input data sets. 
Figure 5. Trends for minimum $\left(t_{\text {count }} \geq 1\right)$, maximum $\left(t_{\text {count }} \geq 9\right)$ and expert-assessed $\left(t_{\text {count }} \geq 6, t_{\text {count }} \geq 1\right)$ thresholds. (a) Trends for changes in the number of all eroded areas based on the three thresholds; (b) trend for changes in the total eroded area.

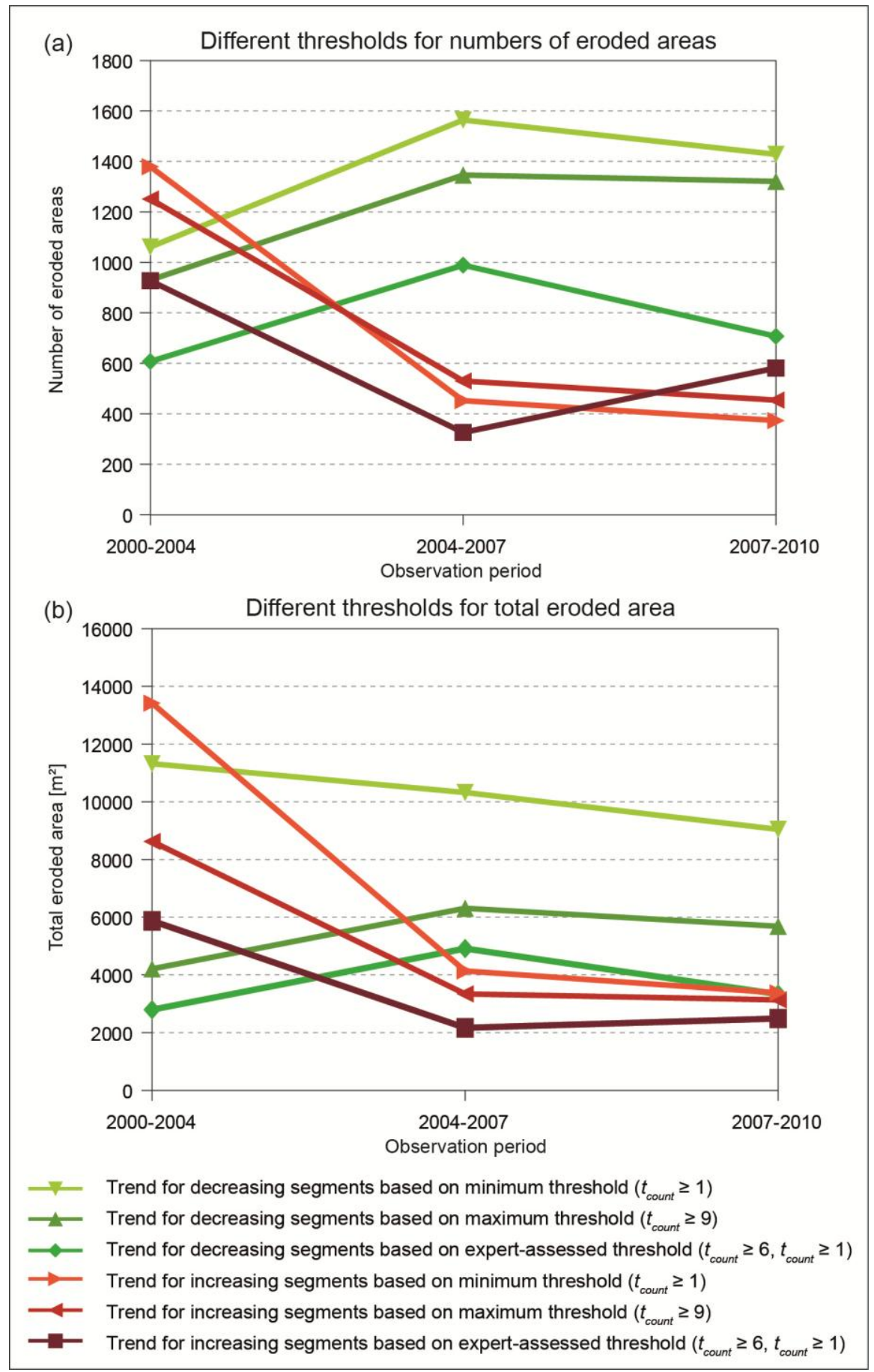

\section{Results}

This section presents the study results: Section 6.1 describes the impact of the selected parameters from Section 5 and Section 6.2 presents the occurrence of eroded area per year (Table 1). In Section 6.3 we investigate qualitative changes of corresponding eroded areas in the three observation periods and differentiate 25 patterns of change (Figure 6). The last Section 6.4 describes the quantitative changes of eroded areas in the three observation periods. 
Table 1. Occurrence of shallow eroded areas in the four years.

\begin{tabular}{ccccc}
\hline & $\mathbf{2 0 0 0}$ & $\mathbf{2 0 0 4}$ & $\mathbf{2 0 0 7}$ & $\mathbf{2 0 1 0}$ \\
\hline Number of eroded areas & 1,018 & 1,202 & 919 & 1,013 \\
Total eroded area $\left(\mathrm{m}^{2}\right)$ & 9,350 & 13,460 & 9,725 & 9,498 \\
Maximum size of e.a.* $\left(\mathrm{m}^{2}\right)$ & 175 & 185 & 188 & 132 \\
\hline
\end{tabular}

* e.a.: eroded area.

Figure 6. Different patterns of changes for the eroded areas depending on their qualitative changes summarized in groups of similar decrease or increase behaviour.

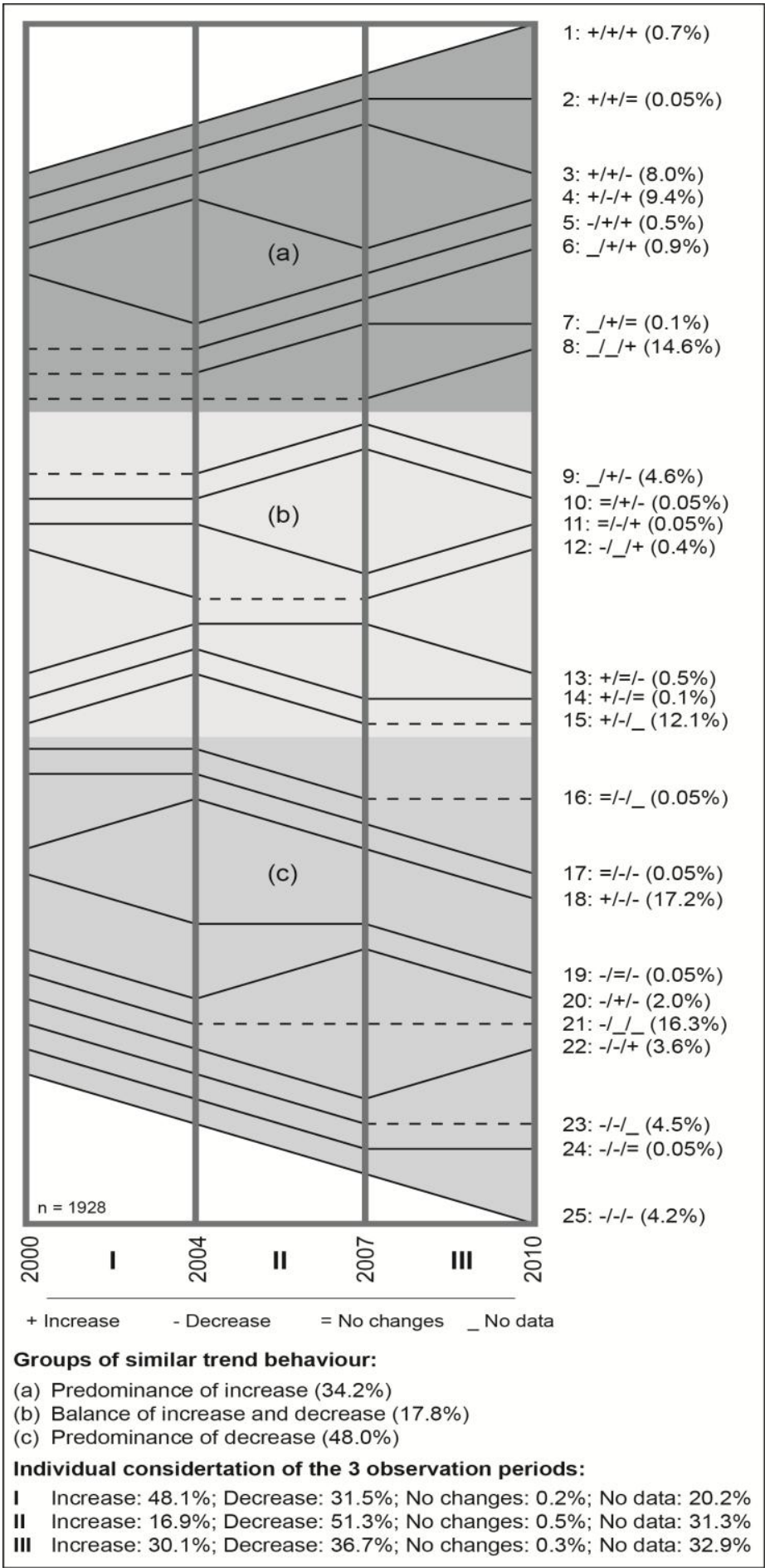




\subsection{Comparison of Minimum, Maximum and Expert-Assessed Thresholds for the Segmentation of} Eroded Areas

A comparison of the minimum $\left(t_{\text {count }} \geq 1\right)$, maximum $\left(t_{\text {count }} \geq 9\right)$ and the expert-assessed $\left(t_{\text {count }} \geq 6\right.$, $\left.t_{\text {count }} \geq 1\right)$ thresholds over the three observation periods reveals similar trends for changes in the number as well as the total size of the eroded areas (Figure 5(a,b)). The values for the expert-assessed eroded areas are often lower than for the minimum and maximum thresholds because some segments were excluded due to the maximum size being set at $200 \mathrm{~m}^{2}$ (Section 6.2). Graphs for expert-assessed increase in numbers differ from those based on minimum and maximum thresholds in that they rise again in the period 2007-2010 instead of decreasing. There are slight deviations in the trends on the total eroded areas based on the minimum threshold for decrease. Most of the trends, however, show a similar behaviour. This means that the overall assessment of changes in eroded areas remains essentially unaltered and hardly affected by any change in the thresholds.

The number of increasing and decreasing segment parts compared to the areas of these segments show the same tendency across the four years, i.e., a predominant increase between 2000 and 2004 and a predominant decrease between 2004-2007 and 2007-2010 (Figure 5(a)). A comparison of the numbers of increasing and decreasing eroded segments with the total area of increasing and decreasing eroded segments, based on the three different thresholds over the 10 year time span, reveals the same trend. In the first period (2000-2004) an increase in numbers and total eroded area dominates, whereas in the two following periods (2004-2007 and 2007-2010) a decrease in numbers and total eroded area prevails (Figure 5(b)).

\subsection{Occurrence of Erosions in the Four Different Years}

Segmentation is conducted for each orthophoto, producing maps containing all eroded areas. Inside the eroded areas little gaps can occur due to sliding vegetated clods. Because these are also part of the eroded area, the gaps are filled and merged with the detected eroded area. A unique ID is assigned to every single eroded area to allow a comparison of corresponding eroded areas in the four different years. According to Schauer [28] and our own field investigations, the target size of the analysed eroded areas ranges from $2 \mathrm{~m}^{2}$ to $200 \mathrm{~m}^{2}$. Smaller eroded areas can represent initial erosion-related forms such as tension fissures, which can be confused with other forms such as trails of grazing animals or large boulders. The boundaries of eroded areas larger than $200 \mathrm{~m}^{2}$ are often characterized by gradual transitions between eroded and undisturbed areas. Hence they do not show distinct boundaries and are difficult to delineate. Each probability map is analysed according to the total amount and the sizes of eroded areas. For the changes of the areas in the three observation periods we differentiate between (i) qualitative changes indicating increase and decrease tendency without considering quantitative changes in size and (ii) quantitative changes describing the measurable changes in the size of eroded areas.

Across the entire test site there were 1,018 classified eroded areas in 2000, 1,202 in 2004, 919 in 2007 and 1,013 in 2010 (Table 1). The properties of all eroded areas show an increase for the number of eroded areas and the total eroded area for the first observation period between 2000 and 2004. The next two periods are characterized by a constantly decreasing number and total size of the eroded area, 
whereas an increase for the number of eroded areas re-occurs between 2007 and 2010 (Table 1). There seems to be an overall trend of one increase followed by a continuous decrease. It is notable that the values of numbers of all eroded areas and total eroded area for 2000 are quite similar to the values in 2010.

\subsection{Qualitative Changes of Classified Eroded Areas between 2000 and 2010}

Qualitative changes describe how many increasing (+), decreasing (-), and unchanged (=) eroded areas are situated in the test site, regardless of the size of the changes. Depending on how often and in which observation period an eroded area increases, decreases or remains unchanged, 25 different patterns of change can be deduced. These 25 different patterns of change could be gathered into three groups of similar trend behaviour (Figure 6).

Over the ten-year observation period, predominantly decreasing eroded areas make up the largest group $(48.0 \%)$, followed by the eroded areas with a tendency to increase (34.2\%). For $17.8 \%$ of eroded areas a balance of enlargement and reduction exists (Figure 6). In this case the size of the erosion remains the same for one observation period, which happens very rarely. Sometimes data are missing for individual periods because an eroded area was not classified in two consecutive years of a period and the remaining two periods balance between increase and decrease. The most frequently occurring pattern of change (Figure 6, pattern 18) corresponds to the overall trend of all classified eroded areas (Section 5.2; Table 1): increases dominating in the first period (2000-2004) followed by two periods (2004-2007 and 2007-2010) in which decreases prevail. Individual consideration of the three observation periods also corresponds to this overall trend. However, looking at the 25 different patterns of change separately, the majority of eroded areas increase and decrease irregularly during the ten-year time span. Nevertheless, it should be noted that half of all patterns occurs less than $1 \%$, therefore these areas should be regarded as exceptions.

\subsection{Quantitative Changes of Classified Eroded Areas between 2000 and 2010}

Quantitative changes describe the measurable changes in size of eroded areas classified in two consecutive years. The number of such areas ranges from $n=682$ in 2000-2004 to $n=796$ in 2004-2007 and $n=638$ in 2007-2010 (Table 2). Looking at the net changes of the total eroded area, we can again observe the overall trend of an increase in the first observation period (2000-2004) and a continuous decrease for the remaining two periods (Table 2), albeit with great differences in the overall size of the reduction.

Table 2. Quantitative net changes of total eroded area.

\begin{tabular}{cccccccccc}
\hline & \multicolumn{2}{c}{$\mathbf{2 0 0 0 - 2 0 0 4}(\mathbf{n}=\mathbf{6 8 2}) *$} & \multicolumn{2}{c}{$\mathbf{2 0 0 4 - 2 0 0 7}(\mathbf{n}=\mathbf{7 9 6}) *$} & \multicolumn{3}{c}{$\mathbf{2 0 0 7 - 2 0 1 0}(\mathbf{n}=\mathbf{6 3 8}) *$} \\
& $\mathbf{2 0 0 0}$ & $\mathbf{2 0 0 4}$ & Net & $\mathbf{2 0 0 4}$ & $\mathbf{2 0 0 7}$ & Net & $\mathbf{2 0 0 7}$ & $\mathbf{2 0 1 0}$ & Net \\
\hline Area $\left(\mathrm{m}^{2}\right)$ & 7,900 & 10,993 & $+3,092$ & 12,082 & 9,324 & $-2,758$ & 8,793 & 7,944 & -849 \\
\hline
\end{tabular}

* Number of detected eroded areas per observation period.

Differentiating the net changes into single increases and decreases per observation period we can see that each period contains enlargement and reduction (Figure 7). The increases differ greatly by up 
to a factor of four. In the first observation period the increase is larger than the decrease resulting in an overall net increase. In the two remaining periods the decrease is larger resulting in a net decrease. In contrast to the increase rates the decrease rates remain fairly constant in the three periods, between $-35.3 \%$ and $-40.7 \%$ (Figure 7 ). There seems to be the same degree of reduction in all observation periods and only the amounts of increase vary and the net changes with them.

Figure 7. Differentiated consideration of quantitative changes.

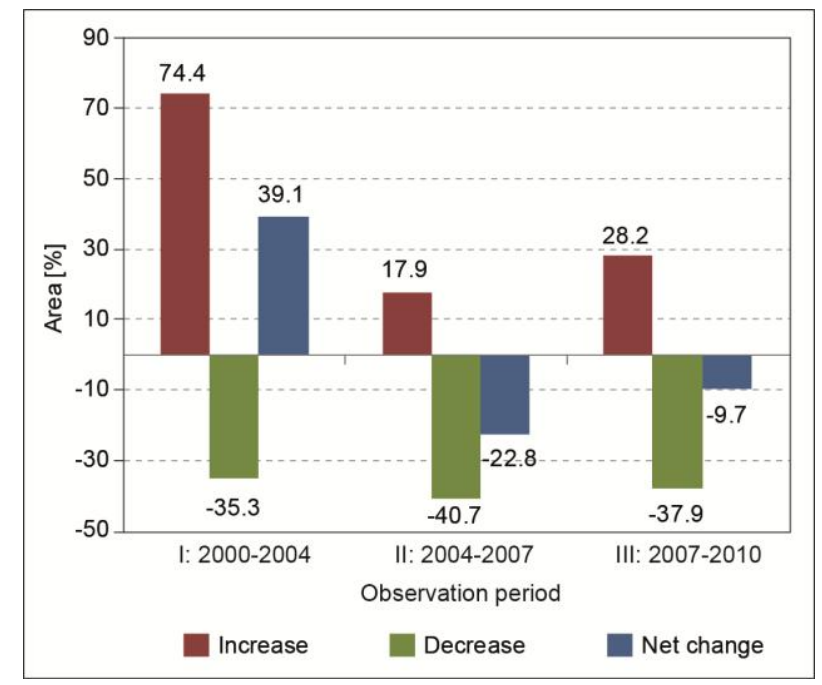

At plot level it is possible to differentiate and evaluate changes on a detailed scale. Considering a single eroded area at four different times allows locating increasing and decreasing parts and drawing conclusions on the processes involved. Example areas with different behaviours are shown in Figure 8.

\section{Discussion}

\subsection{Reliability of Imagery}

The orthophotos used were provided as radiometric and geometric corrected images. Systematic radiometric differences between the images of the individual years were adjusted by histogram matching (Section 3). Remaining unsystematic radiometric differences are taken into account by the implemented segmentation approach (Section 4). Remaining unsystematic geometric differences might influence the analysis of spatial changes in eroded areas in the order of up to $0.25 \mathrm{~m}^{2}$, which has to be taken into account during interpretation.

\subsection{Reliability of Segmentation}

Investigations on the sensitivity of the segmentation method (Section 6.1) suggest that results on trends for increasing and decreasing eroded areas remain comparatively stable against variation in thresholds $\left(t_{\text {count }}\right)$. However, especially the order of decreasing segments is rather sensitive to threshold changes, while increasing segments remain more robust (Figure 5). The adaptation of the dynamic thresholds to the whole test site aims at securing the best possible results for the entire slope. For some areas, however, this can mean misclassifications if the adapted threshold is less well suited to that area. This means that intact areas may be entered as eroded in the classification. 
Figure 8. Example areas for the determination of quantitative changes at plot level.

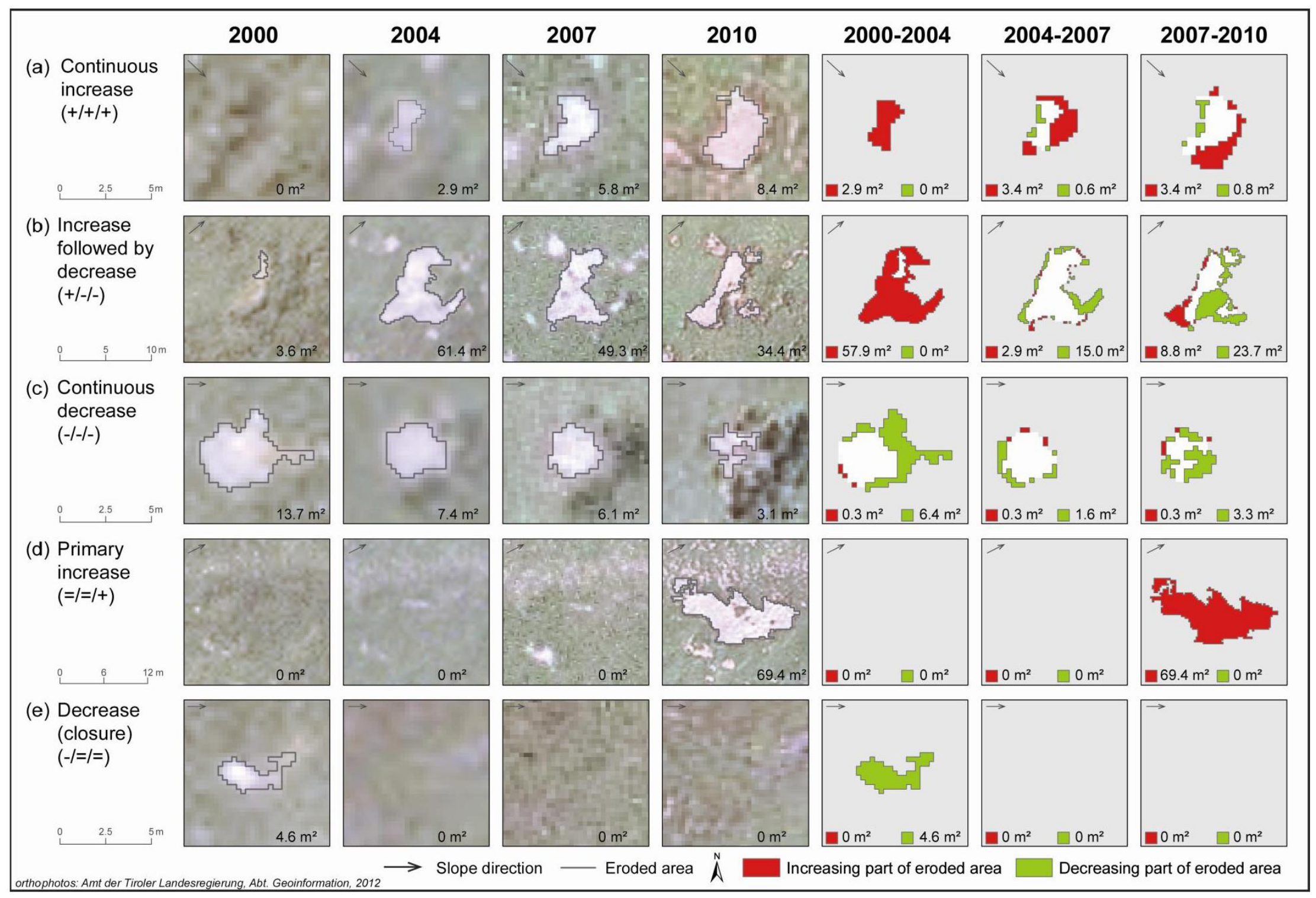




\subsection{Changes in Shallow Erosion Size between 2000 and 2010}

An analysis of all detected eroded areas between 2000 and 2010 shows that in the first study period (2000-2004) erosion areas increased the most. In the two subsequent periods (2004-2007, 2007-2010), the increases amounted to just a quarter of those in the first period. This means that in the first period more and/or stronger eroding events happened, such as severe snow gliding or heavy precipitation, than in the other periods. These erosion events can cause the formation of new eroded areas. They also enlarge existing eroded areas, for example by displacement of material clods in the scarp area [42]. Unlike the variation in increases there is little difference in the decrease of eroded areas. These amount to $35 \%-40 \%$ for a 3-4 year period. The relatively constant decrease of eroded areas is mainly caused by rehabilitation from the surrounding meadow or by pioneer plants [28]. So we have relatively regular decreases of eroded areas on the one hand, and irregularly occurring increases as a result of short-term erosion events, on the other. Figure 6 shows that individual areas behave differently, but there is a noticeable overall trend. All in all, the investigation shows declining erosion activity for the investigated period from 2000 to 2010.

\section{Conclusions and Further Applications}

The automated detection approach using orthophotos from four different years (2000, 2004, 2007, 2010) has proved to be an appropriate method for analysing development trends of small and shallow eroded areas $\left(2-200 \mathrm{~m}^{2}\right)$. Central to the study is an assessment of process dynamics, i.e., whether the erosion areas are predominantly increasing or decreasing.

Compared to manual delineation by an operator, which relies on the individual experiences the presented approach saves time and produces repeatable results. Furthermore, the investigation of the parameter sensitivity and its impact on uncertainty of delineation results give deeper insight to the algorithms behaviour, which is often neglected in classification studies. The investigation of uncertainty based on different parameter settings shows that total number of eroded areas might vary between $20 \%$ and $100 \%$ and total area of erosion might vary even between $25 \%$ and $300 \%$ compared to the expert selected parameters. However, the development trends of increasing and decreasing erosion within each period remain stable except for the increasing features in the study period 2007-2010 (Figure 5).

In each year we detected between 919 and 1,202 eroded areas. For 1,928 eroded areas we demonstrate qualitative changes (regardless of the size of the changes), by deducing 25 different patterns of change (Figure 6). For another 638 to 796 eroded areas we calculated the individual quantitative amount of areal changes (Table 2). In the first study period (2000-2004) erosion areas increased but then decreased in the two subsequent periods (2004-2007 and 2007-2010). Presumably in the first period stronger erosion events occurred than in the two subsequent periods which are dominated by a constant decrease due to rehabilitation of the vegetation.

The method presented is well suited for future long-term monitoring of shallow eroded areas. The ongoing integration of up-to-date aerial photographs will continuously expand the study series. The integration of a high resolution digital terrain model, e.g., from airborne laser scanning would allow an area slope correction for a more reliable quantitative comparison of the spatial extent of the changes in eroded areas. Future classifications in current orthophotos could be compared with reference data from 
field surveys if they are mapped without a great time lag to the image acquisition. Study areas are, however, often remote, very steep and difficult to access, which makes fieldwork rather labour-intensive and time-consuming. For further studies we recommend the usage of unmanned aerial vehicles as an alternative reference data source. With such a modified set-up, following the Soil Conservation Protocol of the Alpine Convention [43], areas endangered by erosion can be mapped and long-term monitoring can be applied to achieve a better understanding of the processes involved.

\section{Acknowledgments}

The authors would like to thank the Austrian Academy of Sciences and the University of Innsbruck for funding the work.

\section{Conflict of Interest}

The authors declare no conflict of interest.

\section{References}

1. MacDonald, D.; Crabtree, J.R.; Wiesinger, G.; Dax, T.; Stamou, N.; Fleury, P.; Gutierrez Lazpita, J.; Gibon, A. Agricultural abandonment in mountain areas of Europe: Environmental consequences and policy response. J. Environ. Manage. 2000, 59, 47-69.

2. Chemini, C.; Rizzoli, A. Land use change and biodiversity conservation in the Alps. J. Mt. Ecol. 2003, 7(Suppl.), 1-7.

3. Tasser, E.; Leitinger, G.; Pecher, C.; Tappeiner, U. Agricultural Changes in the European Alpine Bow and Their Impact on Other Policies. In Proceedings of the 16th Symposium of the European Grassland Federation, Gumpenstein, Austria, 29-31 August 2011; pp. 27-38.

4. Glade, T. Landslide occurrence as a response to land use change: A review of evidence from New Zealand. Catena 2003, 51, 297-314.

5. Tasser, E.; Mader, M.; Tappeiner, U. Effects of land use in alpine grasslands on the probability of landslides. Basic Appl. Ecol. 2003, 4, 271-280.

6. Meusburger, K.; Alewell, C. Impacts of anthropogenic and environmental factors on the occurrence of shallow landslides in an alpine catchment (Urseren Valley, Switzerland). Nat. Hazards Earth Syst. Sci. 2008, 8, 509-520.

7. Soldati, M.; Corsini, A.; Pasuto, A. Landslides and climate change in the Italian Dolomites since the Late glacial. Catena 2004, 55, 141-161.

8. Beniston, M. Mountain weather and climate: A general overview and a focus on climate change in the Alps. Hydrobiologia 2006, 562, 3-16.

9. Crozier, M.J. Deciphering the effect of climate change on landslide activity: A review. Geomorphology 2010, 124, 260-267.

10. Chiang, S.-H.; Chang, K.-T. The potential impact of climate change on typhoon-triggered landslides in Taiwan, 2010-2099. Geomorphology 2011, 133, 143-151.

11. Gobster, P.H.; Nassauer, J.I.; Daniel, T.C.; Fry, G. The shared landscape: What does aesthetics have to do with ecology? Landscape Ecol. 2007, 22, 959-972. 
12. Mantovani, F.; Soeters, R.; Van Westen, C.J. Remote sensing techniques for landslide studies and hazard zonation in Europe. Geomorphology 1996, 15, 213-225.

13. Van Westen, C.J.; Lilie Getahun, F. Analyzing the evolution of the Tessina landslide using aerial photographs and digital elevation models. Geomorphology 2003, 54, 77-89.

14. Metternicht, G.; Hurni, L.; Gogu, R. Remote sensing of landslides: An analysis of the potential contribution to geo-spatial systems for hazard assessment in mountainous environments. Remote Sens. Environ. 2005, 98, 284-303.

15. Moine, M.; Puissant, A.; Malet, J.-P. Detection of Landslides from Aerial and Satellite Images with a Semi-Automatic Method. Application to the Barcelonette Basin (Alpes-de-Haute-Provence, France). In Proceedings of International Conference Landslide Processes: From Geomorphological Mapping to Dynamic Modelling, CERG, Strasbourg, France, 6-7 February 2009; pp. 63-68.

16. Bishop, M.P.; James, L.A.; Shroder, J.F.; Walsh, S.J. Geospatial technologies and digital geomorphological mapping: Concepts, issues and research. Geomorphology 2012, 137, 5-26.

17. Cardinali, M.; Reichenbach, P.; Guzzetti, F.; Ardizzone, F.; Antonini, G.; Galli, M.; Cacciano, M.; Castekkani, M.; Salvati, P. A geomorphological approach to the estimation of landslide hazards and risks in Umbria, Central Italy. Nat. Hazards Earth Syst. Sci. 2002, 2, 57-72.

18. Alewell, C.; Meusburger, K.; Brodbeck, M.; Bänninger, D. Methods to describe and predict soil erosion in mountain regions. Landscape Urban Plan. 2008, 88, 46-53.

19. Van Westen, C.J.; Castellanos, E.; Kuriakose, S.L. Spatial data for landslide susceptibility, hazard, and vulnerability assessment: An overview. Eng. Geol. 2008, 102, 112-131.

20. Hervás, J.; Barredo, J.; Rosin, P.; Pasuto, A.; Mantovani, F.; Silvano, S. Monitoring landslides from optical remotely sensed imagery: The case history of Tessina landslide, Italy. Geomorphology 2003, 54, 63-75.

21. Borghuis, A.M.; Chang, K.; Lee, H.Y. Comparison between automated and manual mapping of typhoon-triggered landslides from SPOT-5 imagery. Int. J. Remote Sens. 2007, 28, 1843-1856.

22. Hay, G.J.; Castilla, G. Geographic Object-Based Image Analysis (GEOBIA): A New Name for A New Discipline. In Object-Based Image Analysis-Spatial Concepts for Knowledge-Driven Remote Sensing Applications; Blaschke, T., Lang, S., Hay, G., Eds.; Springer: Berlin/Heidelberg, Germany, 2008; pp. 75-89.

23. Martha, T.R.; Kerle, N.; Jetten, V.; van Westen, C.J.; Kumar, K.V. Characterising spectral, spatial and morphometric properties of landslides for semi-automatic detection using object-oriented methods. Geomorphology 2010, 116, 24-36.

24. Lu, P.; Stumpf, A.; Kerle, N.; Casagli, N. Object-oriented change detection for landslide rapid mapping. IEEE Geosci. Remote Sens. Lett. 2011, 8, 701-705.

25. Stumpf, A.; Kerle, N. Object-oriented mapping of landslides using Random Forests. Remote Sens. Environ. 2011, 115, 2564-2577.

26. Hölbling, D.; Füreder, P.; Antolini, F.; Cigna, F.; Casagli, N.; Lang, S. A semi-automated object-based approach for landslide detection validated by persistant scatterer interferometry measures and landslide inventories. Remote Sens. 2012, 4, 1310-1336.

27. Van den Eeckhaut, M.; Kerle, N.; Poesen, J.; Hervás, J. Object-oriented identification of forested landslides with derivates of single pulse LiDAR data. Geomorphology 2012, 173-174, 30-42. 
28. Schauer, T. Die Blaikenbildung in den Alpen. Schriftenreihe des Bayerischen Landesamtes für Wasserwirtschaft 1975, 1, 1-29.

29. Van Asch, T.W.J.; Buma, J.; Van Beek, L.P.H. A view on some hydrological triggering systems in landslides. Geomorphology 1999, 30, 25-32.

30. Lateltin, O.; Haemmig, C.; Raetzo, H.; Bonnard, C. Landslide risk management in Switzerland. Landslides 2005, 2, 313-320.

31. Laatsch, W.; Grottenthaler, W. Typen der Massenverlagerung in den Alpen und ihre Klassifikation. Forstwissen. Centralbl. 1972, 91, 309-339.

32. Wiegand, C.; Geitner, C. Flachgründiger Abtrag auf Wiesen- und Weideflächen in den Alpen Wissensstand, Datenbasis und Forschungsbedarf. Mitt. Österr. Geogr. G. 2010, 152, 130-162.

33. Dilo, A.; Kraipeerapun, P.; Bakker, W.; de By, R.A. Storing and Handling Vague Spatial Objects. In Proceedings of the 15th International Workshop on Database and Expert Systems Applications, DEXA, Zaragoza, Spain, 30 August-3 September 2004; pp. 945-950.

34. Fisher, P. Models of Uncertainty in Spatial Data. In Geographical Information Systems: Principles, Techniques, Management and Applications (Volume 1); Longley, P., Goodchild, M.F., Maguire, D.J., Rhind, D.W., Eds.; John Wiley and Sons: New York, NY, USA, 1999; pp. 191-205.

35. Cohen, A.; Gotts, N. The 'egg-yolk' Representation of Regions with Indeterminate Boundaries. In Geographic Objects with Indeterminate Boundaries; Burrough, P.A., Frank, A.U., Eds.; Taylor and Francis: London, UK, 1996; pp. 171-187.

36. Auer, I.; Hiebl, J.; Reisenhofer, S.; Böhm, R.; Schöner, W. ÖKLIM 1971-2000-Aktualisierung des Digitalen Klimaatlas Österreich 1961-1990; Projektendbericht; ZAMG: Wien, Austria, 2010.

37. Brandner, R. Geologie und Tektonik. Geologische und Tektonische Übersichtskarte von Tirol. Begleittexte IX; Tirol Atlas: Innsbruck, Austria, 1985; p. 1.

38. Research Group-Gruppo di Ricerca Consorzio Ferrara Ricerche (CFR). BBT-SE Geological Map 1:25.000 Map Sheets 1 and 2; Universität Innsbruck, Geologische Bundesanstalt (GBA): Innsbruck, Austria, 2006; p. 2.

39. TIRIS. Land Tirol, Amt der Tiroler Landesregierung-Tiris, 2010.

40. Lillesand, T.M.; Kiefer, R.W.; Chipman, J.W. Remote Sensing and Image Interpretation; Wiley and Sons: New York, NY, USA, 2008.

41. Frank, A. Why is Scale an Effective Descriptor for Data Quality? The Physical and Ontological Rationale for Imprecision and Level of Detail. In Research Trends in Geographic Information Science; Navratil, G., Ed.; Springer: Berlin/Heidelberg, Germany, 2009; pp. 39-57.

42. Auerswald, K. Gravitative Bodenverlagerung. In Bodenerosion und Bodenschutz-Analyse und Bilanz eines Umweltproblems; Richter, G., Ed.; Wiss. Buchges.: Darmstadt, Germany, 1998; pp. 61-67.

43. CIPRA. Alpine Convention Protocol on the Implementation of the Alpine Convention of 1991 in the field of soil conservation. Offic. J. Eur. Union 2005, 48, 29-35.

(C) 2013 by the authors; licensee MDPI, Basel, Switzerland. This article is an open access article distributed under the terms and conditions of the Creative Commons Attribution license (http://creativecommons.org/licenses/by/3.0/). 